\title{
Determination of Eugenol in Personal-Care Products by Dispersive Liquid-Liquid Microextraction Followed by Spectrophotometry Using $p$-Amino- $N, N$-dimethylaniline as a Derivatizing Agent
}

\author{
Bahaa Malik Altahir ${ }^{1, *}$, Omar Abdulazeez $^{1}$, Sarmad Bahjat Dikran ${ }^{2 \ddagger}$, and Keith Edward Taylor ${ }^{3}$ \\ ${ }^{1}$ Department of Biology, College of Science, University of Baghdad, Baghdad 10071, Iraq \\ ${ }^{2}$ Department of Chemistry, College of Education for Pure Science - Ibn Al-Haitham, University of Baghdad, Baghdad 10071, Iraq \\ ${ }^{3}$ Department of Chemistry and Biochemistry, University of Windsor, 401 Sunset Avenue, Windsor, Ontario N9B 3P4, Canada
}

\section{*Corresponding author:}

tel: +964-7901567986

email:baha782004@gmail.com

Received: June 23, 2020

Accepted: September 11, 2020

DOI: $10.22146 /$ ijc.56198

¥This paper is dedicated to the memory of the late Sarmad Bahjat Dikran.

Deceased July 6, 2020

\begin{abstract}
Two simple methods for the determination of eugenol were developed. The first depends on the oxidative coupling of eugenol with $\mathrm{p}$-amino-N,N-dimethylaniline $(P A D A)$ in the presence of $K_{3}\left[\mathrm{Fe}(\mathrm{CN})_{6}\right]$. A linear regression calibration plot for eugenol was constructed at $600 \mathrm{~nm}$, within a concentration range of 0.25-2.50 $\mu \mathrm{g} . \mathrm{mL}^{-1}$ and a correlation coefficient $(r)$ value of 0.9988. The limits of detection (LOD) and quantitation (LOQ) were 0.086 and $0.284 \mu g . m L^{-1}$, respectively. The second method is based on the dispersive liquid-liquid microextraction of the derivatized oxidative coupling product of eugenol with PADA. Under the optimized extraction procedure, the extracted colored product was determined spectrophotometrically at $618 \mathrm{~nm}$. A linear plot within a concentration range of 0.05-1.65 $\mu \mathrm{g} \cdot \mathrm{mL}^{-1}(r=0.9997)$ was constructed. The LOD and LOQ were 0.053 and $0.177 \mu g . m L^{-1}$, respectively. Both methods were tested for the analysis of eugenol in commercial personal-care products, and the results confirmed that the procedures are accurate, precise, and reproducible (RSD < 1\%).
\end{abstract}

Keywords: dispersive liquid-liquid microextraction; derivatizing agent; eugenol; pamino-N,N-dimethylaniline

\section{- INTRODUCTION}

Eugenol (E) $\left(\mathrm{C}_{10} \mathrm{H}_{12} \mathrm{O}_{2}\right.$; 4-allyl-2-methoxy phenol) is a phenylpropene or allylbenzene [1]. It is a component of aromatic plants, such as wormwood, clove, celery, cinnamon, and ginger [2]. Due to its potent antimicrobial and antioxidant properties, eugenol has been widely used in cosmetics and pharmaceuticals [3]. It is useful in dentistry to increase the protection against oxidative injury, periodontal ligament fibroblasts, and prosthodontic uses [4]. This compound has recognized acaricidal activity, including activity on R. microplus [5]. Despite these benefits of eugenol, there are also caveats about its use, including allergenicity, cause of some skin diseases, toxicity, generation of reactive oxygen species, enzyme inhibition, carcinogenicity, and geno-, immuno-, cyto- toxicity [6].
Analytical techniques, such as spectrophotometry, currently provide the ability to measure many pharmaceutical compounds down to low levels in conjunction with modern extraction techniques, i.e., derivatization and clean-up methods [7]. Sample preparation is one of the most critical aspects of such organic analytical procedures [8]. The extraction of pharmaceuticals from prepared samples into a limited solvent amount is the first and most critical step [9]. Analysis requires careful standardization and preanalytical handling of the samples [10]. However, matrix effects, such as the presence of macromolecules, small molecules, additives and/or salts, interfere with analysis [11]. Careful sample preparation is needed for the low analyte concentration and to overcome the biological matrix effect, which is incompatible with the instrumental 
technique chosen. Thus, careful sample preparation should be used to overcome matrix effects, starting with enhancing the selectivity and sensitivity of the study to improve analytical criteria and/or protect the analytical instrument from potential harm [12]. Several techniques may be used to do this, the most common being liquid-liquid extraction, solid-phase microextraction (SPME), solid-phase extraction (SPE), and soxhlet extraction processes [9].

Dispersive liquid-liquid microextraction techniques (DLLME) have been used recently for the preconcentration of organic analytes from aqueous matrices [13]. The process has the benefits of low consumption of organic solvents, a high extraction efficiency, short extraction time, and high enrichment factors [14]. The main objective of microextraction is to obtain a reproducible, representative amount of the analyte from the sample rather than to retrieve all of the analyte [15].

Eugenol has also been determined using liquid chromatography [16] provided with electrochemical [1718] or UV detection [19], voltammetric [20], photodiode array (PDA) [21] and oscillating methods [22]. These methods are accurate and efficient, but they have some drawbacks such as complexity, expense, and timeconsuming. The proposed methods are simple, low cost, and quick.

Chemical derivatization is used to transform a molecule into a derivative that has better properties for the intended study and enhances the sensitivity through an easy, rapid reaction that forms a highly stable and reproducible derivative [23].

The aim of this study was to propose and optimize an accurate and time-effective method for the quantitative estimation of eugenol in personal-care products with a combination of spectrophotometry and pre-extraction using the DLLME technique. The pre-treatment method was enhanced by a derivatization step using a new derivatizing agent, para-amino- $N, N$-dimethylaniline (PADA), where derivatization was accomplished by oxidative coupling. A current literature survey found that no previous study focused on the existence of eugenol in personal-care products. In addition, no study presented a reagent for eugenol derivatization and simple spectrophotometric detection in the visible region.

\section{- EXPERIMENTAL SECTION}

\section{Materials}

The primary reference standard was (eugenol 4$\left.\left(\mathrm{H}_{2} \mathrm{C}=\mathrm{CHCH}_{2}\right) \mathrm{C}_{6} \mathrm{H}_{3}-2-\left(\mathrm{OCH}_{3}\right) \mathrm{OH}\right)$. Para-amino-N,Ndimethylaniline4-dimethylamino) aniline 97\%, potassium hexacyanoferrate(III) $\left(\mathrm{K}_{3} \mathrm{Fe}(\mathrm{CN})_{6}\right) \quad 99 \%$, potassium hydroxide pellets $(\mathrm{KOH}) \geq 85 \%$, ammonia solution $25 \%\left(\mathrm{NH}_{4} \mathrm{OH}\right)$, potassium chloride $(\mathrm{KCl})$ 99.0\%, methanol $\left(\mathrm{CH}_{3} \mathrm{OH}\right) \geq 99.9 \%$, chloroform $\left(\mathrm{CHCl}_{3}\right) \geq 99.8 \%$, analytical grade of ethanol $\left(\mathrm{CH}_{3} \mathrm{CH}_{2} \mathrm{OH}\right) \geq 99.8 \%$, acetone $\left(\mathrm{CH}_{3} \mathrm{COCH}_{3}\right) \geq 99.5 \%$, and acetonitrile $\left(\mathrm{CH}_{3} \mathrm{CN}\right) \geq 99.9 \%$ were used as dispersive solvents and were purchased from Sigma Aldrich (Baghdad, Iraq). Dichloromethane $\left(\mathrm{CH}_{2} \mathrm{Cl}_{2}\right) \geq$ 99.5\%, chloroform $\left(\mathrm{CHCl}_{3}\right) \geq 99.8 \%$, and carbon tetrachloride $\left(\mathrm{CCl}_{4}\right) \quad 99.5 \%$ were used as extraction solvents and were obtained from VWR (Leicestershire, England). Solutions were prepared in double-distilled water. Other required salts were of $>98 \%$ purity.

\section{Instrumentation}

A Cary 100 double-beam UV-Vis spectrophotometer (Mulgrave, Victoria, Australia) with $1 \mathrm{~cm}$ matched quartz cells was used for all spectrophotometric measurements. $\mathrm{pH}$ measurements were carried out with an EA940 $\mathrm{pH}$ meter supplied with a stainless steel micro $\mathrm{pH}$ probe from Orion (Beverly, MA, USA); calibration buffers of $\mathrm{pH} 4.0,7.0$, and 10.0 were purchased from VWR (Batavia, USA). A DT$2234 \mathrm{~A}+$ ONPhoto, Shenzhen Liweihui (Guangdong, China) digital tachometer was used to regulate the rpm speed of centrifugation. A Genie 2 vortex mixer (Scientific Industries, Inc., Bohemia, NY6), an Elmasonic S 300 bath sonicator, Elma (Singen, Germany), and a Corning (Tewksbury, MA, USA) LSE TM Compact centrifuge holding $6 \times 15 \mathrm{~mL}$ centrifuge tubes and having a maximum speed of $6000 \mathrm{rpm}$, were used to enhance phase separation. Eugenol was weighed by the Sartorius Analytic MC1 balance (Sartorius, Göttingen, Germany). 


\section{Procedure}

\section{General derivatization procedure}

Aliquots of a sample containing $0.25-2.5 \mathrm{mg}$ of eugenol were transferred into a series of $50 \mathrm{~mL}$ standard flasks. A volume of $1.5 \mathrm{~mL}$ of $10 \mathrm{mM}$ PADA solution, $1.5 \mathrm{~mL}$ of $20 \mathrm{mM}$ potassium hexacyanoferrate(III) and $1.5 \mathrm{~mL}$ of $100 \mathrm{mM}$ potassium hydroxide solution were added in that order. The contents of the flasks were brought to volume with distilled water, mixed well, and left to stand for $5 \mathrm{~min}$. The absorbance was measured at $600 \mathrm{~nm}$ (at room temperature $25^{\circ} \mathrm{C}$ ) against a reagent blank containing all materials except eugenol. A calibration curve was plotted, and the regression analysis data were obtained (Table 1).

\section{General DLLME procedure}

In a $16 \mathrm{~mL}$ plastic sealed centrifuge tube, $14 \mathrm{~mL}$ of the formed, colored derivative solution was transferred. Then, $550 \mu \mathrm{L}$ of chloroform as the extracting solvent was added to this solution, followed by the addition of $100 \mu \mathrm{L}$ of methanol as a dispersive solvent and $132 \mu \mathrm{L}$ of $3 \mathrm{M}$ sodium chloride as a salt. After shaking by hand, a cloudy dispersion of the solvent mixture was formed, which was centrifuged for $20 \mathrm{~min}$ at $2500 \mathrm{rpm}$. Finally, $450 \mu \mathrm{L}$ of the organic phase was transferred by syringe into a microcuvette for spectrophotometric determination of eugenol at $618 \mathrm{~nm}$. A calibration curve was plotted, and the regression analysis data were obtained (Table 1).

\section{Analysis of commercial personal-care products}

Eugenol was determined in different samples of mouthwashes, hand washes, and cosmetics. The samples were analyzed according to the proposed method, and sample dilution was applied for samples with eugenol concentration above the linearity range. The samples were determined by the general derivatization and extracted by the DLLME procedure. Spiked samples were prepared for recovery determination by adding $0.5 \mathrm{~mL}$ of $10 \mu \mathrm{g} \cdot \mathrm{mL}^{-1}$ of eugenol [24].

\section{- RESULTS AND DISCUSSION}

Eugenol was determined by two consecutive methods: the first was the direct spectrophotometric measurement based on derivatization via an oxidative coupling reaction. The second utilized the DLLME procedure for the extraction of the derivative into a small volume of organic solvent. The optimum parameters of both methods were achieved. For the direct oxidative coupling method, optimization included the type and concentration of the oxidant and base in addition to the concentration of the coupling reagent and the order of additions. On the other hand, optimization of the DLLME involved the type and volume of the extraction solvent and dispersive solvent, the type and concentration of the salt solution, and the speed and time of centrifugation.

The results confirmed the success of both methods as inexpensive and highly accurate, sensitive methods for the determination of eugenol in different pharmaceutical and medical preparations. The combination of DLLME with the known advantage of the direct oxidative coupling method gave an additional advantage in decreasing both the sample volume and the reagent consumption, increasing the sensitivity and selectivity by using a selective derivatization reagent, i.e., para-amino- $N, N$-dimethylaniline.

\section{Optimization Study of Derivatization Reaction}

The oxidative coupling reaction mechanism was proposed by Faust and Anderson [25], in which a colored dye containing a quinone imine structure is produced. The oxidized form of the amino group of PADA produced by $\mathrm{K}_{3} \mathrm{Fe}(\mathrm{CN})_{6}$, i.e., the imino cation, couples with the eugenol phenolic ring via an electrophilic attack at the para-position [26]. The $\lambda_{\max }$ of $p$-quinoid chromophore formed was shifted into the visible region as a blue-colored solution was formed [27] (Scheme 1).

The optimization of the experimental parameters affecting the formation of the colored product was carried out when an aliquot of eugenol standard solution containing $1.642 \mathrm{mg}$ was mixed with $0.2 \mathrm{mM}$ coupling reagent in a final volume of $50 \mathrm{~mL}$. The type and concentration of the oxidant used were studied, including hexacyanoferrate, potassium iodate, potassium permanganate, potassium dichromate, ammonium thiosulfate, and sodium paraperiodate (data shown for the latter five oxidants in Supplementary Material Fig. A). 


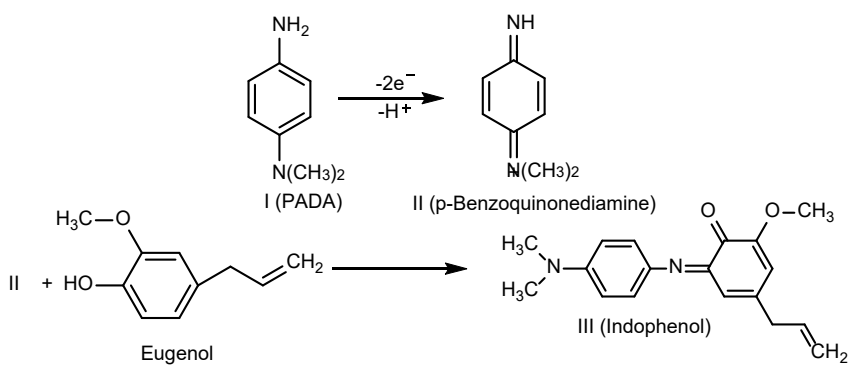

Scheme 1. The proposed mechanism of eugenol coupling [26]

The study shows $0.6 \mathrm{mM}$ hexacyanoferrate was optimal for $0.2 \mathrm{mM}$ eugenol (Fig. 1) when the reaction medium was rendered alkaline with a $2 \mathrm{mM}$ solution of ammonium hydroxide.

The absorbance decreased at low and high concentrations of hexacyanoferrate. The decrease at low concentration may be due to the interference from unreacted materials. The decrease at high concentration may be due to the formation of side products of the reaction and a bathochromic spectral shift effect [28]. Amine reagent oxidation can occur at too high concentrations of $\mathrm{K}_{3} \mathrm{Fe}(\mathrm{CN})_{6}$ [27].

Moreover, the alkaline medium accelerates the oxidative coupling by deprotonating the anilinium group [26]. Amongst various bases, including sodium hydroxide, ammonium hydroxide, potassium hydroxide, and sodium carbonate, a final concentration of $3 \mathrm{mM}$ potassium hydroxide was selected (Fig. 2) to provide the optimum reaction medium since higher amounts of base led to a decrease in the color intensity of the extracted product (data are given in Supplemental Fig. B for bases other than $\mathrm{KOH}$ ). PADA concentration was optimized in the range of $0.02-0.6 \mathrm{mM}$ (Fig. 3), and the concentration of $0.3 \mathrm{mM}$ was chosen for the optimum concentration equivalent to $0.2 \mathrm{mM}$ of eugenol. Despite the stoichiometric requirement for PADA:eugenol of 1 , excess of the oxidized form of PADA can increase the anilinium attack. In any case, in the method being developed, the eugenol is an unknown, and there must be enough/excess PADA present to react with all of the eugenol expected [29]. Finally, to investigate the behavior of the oxidative coupling reaction of eugenol with PADA, the order of reagent addition was investigated to achieve the best sequence of the addition of reactants. The order of analyte, coupling reagent, oxidant, and then the base was selected and maintained throughout the experiment (data are given in Supplementary Material Table A). This

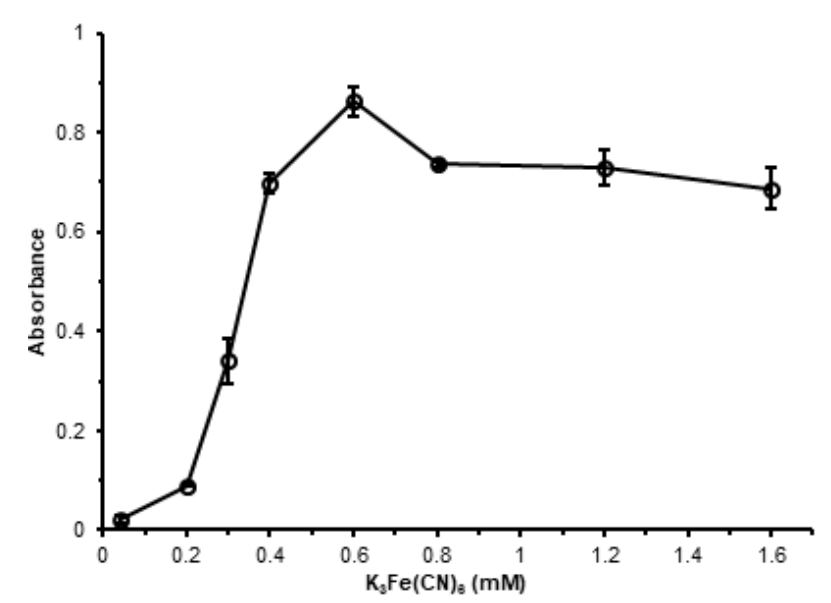

Fig 1. Hexacyanoferrate optimization. Conditions: Eugenol and PADA $0.2 \mathrm{mM}$, ammonium hydroxide $2 \mathrm{mM}$

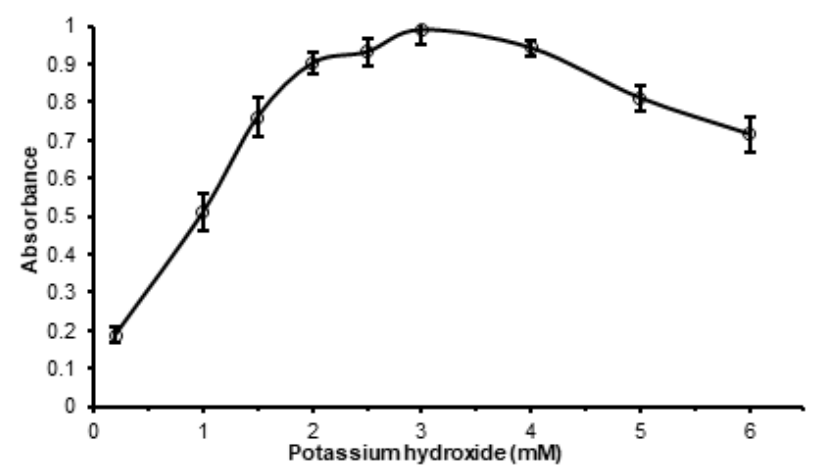

Fig 2. Potassium hydroxide optimization. Conditions: eugenol and PADA $0.2 \mathrm{mM}$, hexacyanoferrate $0.6 \mathrm{mM}$

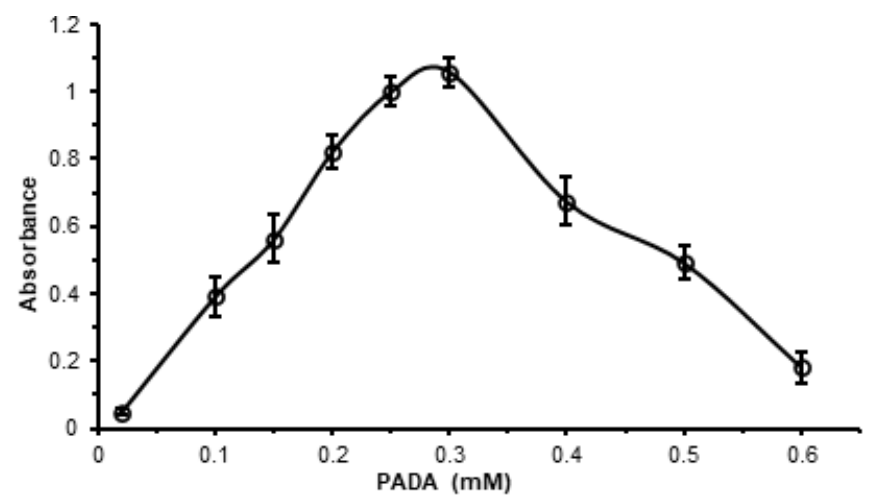

Fig 3. PADA optimization. Conditions: eugenol $0.2 \mathrm{mM}$, hexacyanoferrate $0.6 \mathrm{mM}$, potassium hydroxide $3 \mathrm{mM}$ 
order confirmed the rapid coupling of the reactants. The chromophore formed shows reasonable stability versus time, no significant change in its absorbance was observed in $1 \mathrm{~h}$ after dilution to the final volume.

\section{Optimization of DLLME Method}

In comparison to the direct measurement of eugenol, an efficient extraction (with respect to extraction selectivity, sensitivity, and low detection limit) was possible with the derivatized analyte (i.e., its oxidative coupling product). The optimum conditions for the extraction were established by variation of the type and volume of the extraction solvent, dispersive solvent, and the salt used, in addition to the centrifugation time and speed.

A number of water-immiscible organic solvents with different densities than water and good abilities for analyte solvation were tested to achieve the best extraction [30]. The solvents were added to $14 \mathrm{~mL}$ of the derivatization reaction mixture from $0.2 \mathrm{mM}$ eugenol. $350 \mu \mathrm{L}$ of 1,2-dichloroethane, chloroform, or carbon tetrachloride was tested, using $25 \mu \mathrm{L}$ of acetone as the dispersive solvent and $94 \mu \mathrm{L}$ of $3 \mathrm{M}$ potassium chloride, i.e., $20 \mathrm{mM}$ final concentration of the salt. Among them, 1,2-dichloroethane was chosen in terms of the distribution ratio " $D$ " since the order in which the $D$ value decreased was 1,2-dichloroethane $>$ chloroform $>$ carbon tetrachloride (data in Supplementary Material Fig. C). Using this solvent led to a redshift in the value of $\lambda_{\max }$ of eugenol from $600 \mathrm{~nm}$ (in water) to $618 \mathrm{~nm}$ (in 1,2dichloroethane).

The next step was to examine the optimum volume of the organic phase) in the range of $50-950 \mu \mathrm{L}$ (with $14 \mathrm{~mL}$ of the derivatization reaction mixture from $0.2 \mathrm{mM}$ eugenol) to achieve the highest $\mathrm{D}$-value and a reasonably good enrichment factor (EF). A volume of $550 \mu \mathrm{L}$ was chosen (data for 1,2-dichloroethane, Fig. 4) as the best volume in terms of $\mathrm{D}$ and $\mathrm{EF}$, and this volume is appropriate for subsequent spectrophotometric analysis or HPLC. The potency of different dispersive solvents towards the extraction efficiency, namely, ethyl acetate, ethanol, methanol, acetone, and acetonitrile, was investigated (data are given in Supplementary Material
Fig. D). The investigation showed that the value of $\mathrm{D}$ was in the order of methanol $>$ acetone $>$ ethyl acetate $>$ acetonitrile $>$ ethanol; therefore, methanol was chosen to promote the extraction. Different volumes of $\mathrm{CH}_{3} \mathrm{OH}$ (5-500 $\mu \mathrm{L}$ ) were tested (Fig. 5), and a volume of $100 \mu \mathrm{L}$ of the dispersive solvent was found to be optimal. Higher volumes tended to decrease the extraction efficiency, which could be attributed to an increase in the dye solubility in the aqueous phase.

Generally, the ionic strength or salt effect tends to decrease the solubility of analytes in the aqueous phase and tends to increase the water immiscibility of organic solvent [30]. Therefore, the ionic strength of the aqueous phase was adjusted to increase the extraction yield. This was accomplished by examining the effect of the presence of the three salts (potassium chloride, sodium

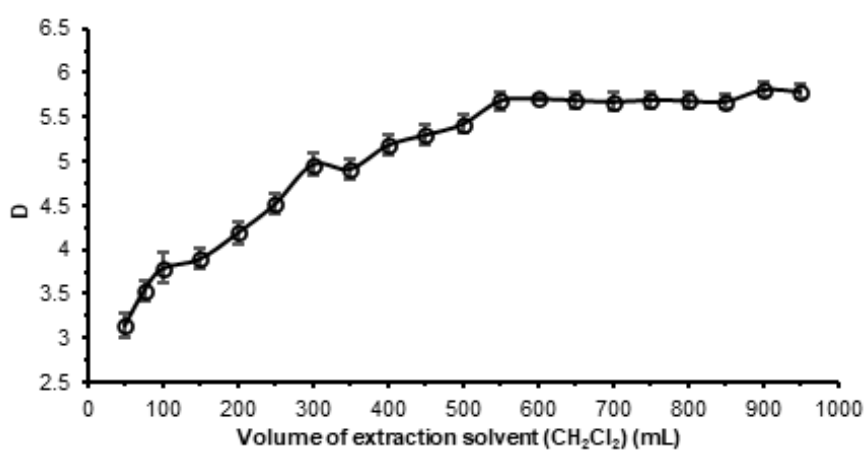

Fig 4. DLLME extraction solvent volume study. Conditions: eugenol $0.2 \mathrm{mM}$, dispersive solvent (acetone) $25 \mu \mathrm{L}$, aqueous phase (dye) $14 \mathrm{~mL}, \mathrm{KCl} 20 \mathrm{mM}$, centrifugation $5 \mathrm{~min}$ at $1100 \mathrm{rpm}$

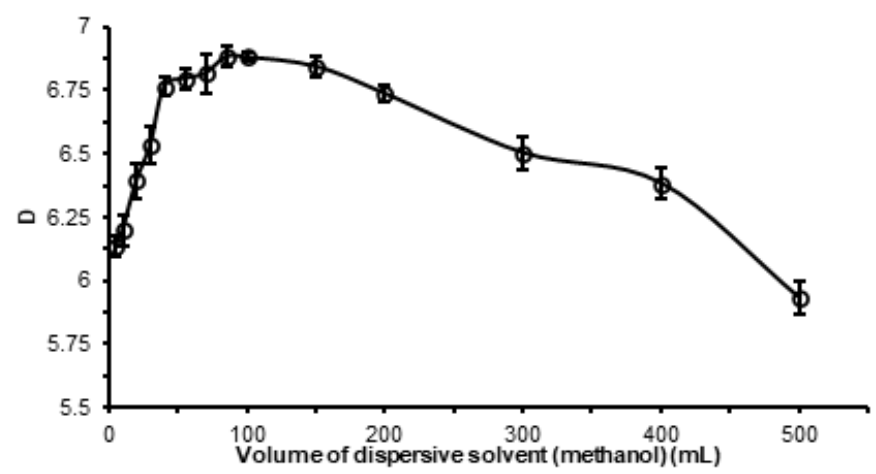

Fig 5. DLLME dispersive solvent volume study. Conditions: eugenol $0.2 \mathrm{mM}$, extraction solvent $550 \mu \mathrm{L}$, aqueous phase (dye) $14 \mathrm{~mL}, \mathrm{KCl} 20 \mathrm{mM}$, centrifugation time $5 \mathrm{~min}$ and centrifugation speed $1100 \mathrm{rpm}$ 
chloride, and ammonium sulfate) on the value of $\mathrm{D}$ (data are given in Supplementary Material Fig. E). The order of the $\mathrm{D}$ values was sodium chloride $>$ potassium chloride $>$ ammonium sulfate. Then, sodium chloride at different final concentrations (2-60 mM) was examined. Although the presence of the salt showed no great effect on the value of the distribution ratio (Fig. 6), $28 \mathrm{mM}$ was chosen as the best concentration.

The separation of phases in DLLME is generally carried out by centrifugation. Moreover, the centrifugal force can affect the partitioning of dye between the aqueous and organic phases and the mass transfer activity $[13,31]$. Both the time needed to attain the best phase separation and the centrifugation speed required for that purpose were studied, Fig. 7, showing that $2500 \mathrm{rpm}$ for $20 \mathrm{~min}$ was enough to attain quantitative separation.

Finally, different methods of reagent mixing (i.e., hand mixing, ultrasound mixing, and vortexing) experiments were conducted. The results (data are given in Supplementary Material Fig. F) proved that no difference in extraction efficiency was obtained; hence, hand mixing was preferred for convenience.

\section{Calibration Curve and Validation Study}

Table 1 shows a summary of regression parameters and other optical characteristics and statistical data of the developed methods. As expected, the method based on DLLME was applicable to a lower concentration range of eugenol due to the preconcentration of the analyte. Moreover, the liquid-liquid microextraction method shows a higher value of $\varepsilon_{\max }$ and hence a lower detection limit.

\section{Analytical Application}

The application of the method for determining eugenol in commercial personal-care products was tested
(Table 2) using the DLLME procedure because of its selectivity, ability to decrease the matrix effect, and high molar extinction coefficient (Table 1). Although the direct method is simpler and the DLLME method is a longer procedure, Table 1 shows the superiority of the

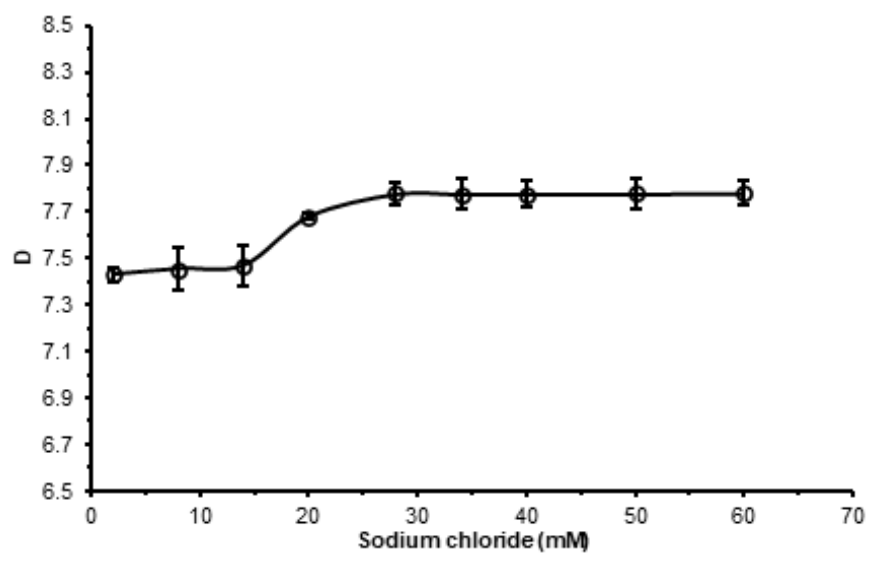

Fig 6. DLLME effect of sodium chloride. Conditions: eugenol $0.2 \mathrm{mM}$, extraction solvent $550 \mu \mathrm{L}$, dispersive solvent $100 \mu \mathrm{L}$, aqueous phase (dye) was $14 \mathrm{~mL}$, centrifugation time $5 \mathrm{~min}$ and centrifugation speed $1100 \mathrm{rpm}$

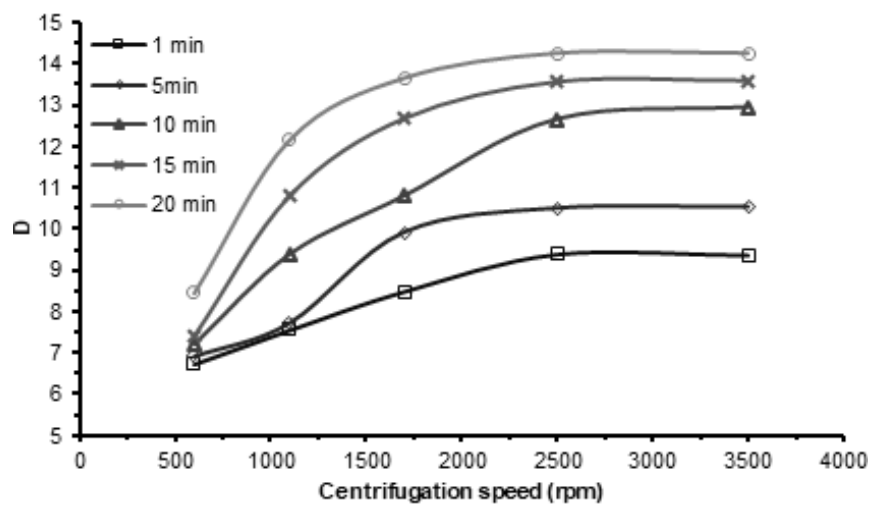

Fig 7. DLLME centrifugation speed and time study. Conditions: eugenol $0.2 \mathrm{mM}$, sodium chloride $28 \mathrm{mM}$, extraction solvent $550 \mu \mathrm{L}$, dispersive solvent $100 \mu \mathrm{L}$, aqueous phase (dye) $14 \mathrm{~mL}$

Table 1. Regression equation, correlation coefficient, linear range, LOD, LOQ, and molar absorptivity of the proposed method $^{*}$

\begin{tabular}{lccccccc}
\hline Method & Slope & $\mathrm{y}$-intercept & $\begin{array}{c}\text { Correlation } \\
\text { coefficient }\end{array}$ & $\begin{array}{c}\text { Linear range } \\
\left(\mu \mathrm{g} . \mathrm{mL}^{-1}\right)\end{array}$ & $\begin{array}{c}\text { LOD } \\
\left(\mu \mathrm{g} \cdot \mathrm{mL}^{-1}\right)\end{array}$ & $\begin{array}{c}\text { LOQ } \\
\left(\mu \mathrm{g} . \mathrm{mL}^{-1}\right)\end{array}$ & $\begin{array}{c}\text { Molar absorptivity } \\
\left(\mathrm{L} \cdot \mathrm{mol}^{-1} \cdot \mathrm{cm}^{-1}\right)\end{array}$ \\
\hline $\begin{array}{l}\text { Derivatization } \\
\text { reaction }\end{array}$ & $0.0871 \pm 0.0010$ & $0.027 \pm 0.002$ & 0.9976 & $0.25-2.5$ & 0.056 & 0.172 & $14300 \pm 200$ \\
DLLME & $0.1813 \pm 0.002$ & $0.0114 \pm 0.002$ & 0.9981 & $0.05-1.7$ & 0.038 & 0.117 & $27800 \pm 400$ \\
\hline
\end{tabular}


Table 2. Recovery (\%) of proposed methods in the determination of eugenol in different products

\begin{tabular}{lcccc}
\hline \multirow{2}{*}{ Product Mouthwash } & \multicolumn{4}{c}{ Proposed methods } \\
\cline { 2 - 5 } & \multicolumn{3}{c}{ Direct } & \multicolumn{3}{c}{ DLLME } \\
\cline { 2 - 5 } & Conc. $\left(\mu \mathrm{g} \cdot \mathrm{mL}^{-1}\right)$ & Recovery $(\%)^{\mathrm{a}}$ & Conc. $\left(\mu \mathrm{g} \cdot \mathrm{mL}^{-1}\right)$ & Recovery $(\%)^{\mathrm{a}}$ \\
\hline Zak & 117 & $100.1 \pm 0.3$ & 118 & $99.4 \pm 0.2$ \\
Kin & 244 & $100.0 \pm 0.4$ & 244 & $99.7 \pm 0.3$ \\
Paradontax & 74.6 & $99.2 \pm 0.9$ & 74.1 & $100.3 \pm 0.6$ \\
Handwash & 17.5 & $99.8 \pm 0.8$ & 17.6 & $100.7 \pm 0.7$ \\
Lifeboy & & & & \\
Cosmetic & 27.6 & $100.4 \pm 0.7$ & 27.5 & $100.3 \pm 0.8$ \\
Lakos & & &
\end{tabular}

Table 3. Previous methods and proposed methods in the determination of eugenol

\begin{tabular}{|c|c|c|c|c|c|c|c|c|}
\hline Method & $\begin{array}{c}\text { Dynamic range } \\
\left(\mu \mathrm{g} \cdot \mathrm{mL}^{-1}\right)\end{array}$ & $\begin{array}{c}\text { LOD } \\
\left(\mu \mathrm{g} \cdot \mathrm{mL}^{-1}\right)\end{array}$ & $\begin{array}{c}\text { LOQ } \\
\left(\mu \mathrm{g} \cdot \mathrm{mL}^{-1}\right)\end{array}$ & Speed & Cost & Easiness & Application & Reference \\
\hline $\begin{array}{l}\text { HPLC amperometric } \\
\text { detection }\end{array}$ & $0.16-16.42$ & 0.052 & 0.157 & Low & High & Low & $\begin{array}{l}\text { plants and pharmaceutical } \\
\text { form }\end{array}$ & [17] \\
\hline HPLC-UV & $0.4-10$ & 0.05 & 0.2 & Low & High & Low & $\begin{array}{l}\text { methanolic extracts of some } \\
\text { spices }\end{array}$ & [19] \\
\hline C18-RP-HPLC-PDA & $5-1000$ & 0.44 & 1.34 & Low & High & Low & $\begin{array}{l}\text { developed nanoemulsion gel } \\
\text { and nanoparticles }\end{array}$ & {$[21]$} \\
\hline HPTLC & $200-1200$ & 33.0 & 46.6 & Low & High & Low & $\begin{array}{l}\text { herbal extract of Ocimum } \\
\text { sanctum }\end{array}$ & [16] \\
\hline Voltammetric & $2.5-202$ & 0.62 & 2.1 & Medium & High & low & essential oils & {$[20]$} \\
\hline $\begin{array}{l}\text { HPLC electrochemical } \\
\text { detection }\end{array}$ & $0.01-10$ & 0.0097 & 0.032 & Low & High & Low & aromatic plants & [18] \\
\hline Oscillating system & $0.082-2.052$ & 0.0821 & & Medium & High & Medium & aq ethanol sample & {$[22]$} \\
\hline \multicolumn{9}{|c|}{ Proposed methods } \\
\hline Derivatization reaction & $0.25-2.5$ & 0.056 & 0.172 & High & Low & High & personal-care products & \\
\hline DLLME & $0.05-1.7$ & 0.038 & 0.117 & High & Low & High & personal-care products & \\
\hline
\end{tabular}

DLLME method; therefore, it was chosen for the purpose of real sample analyses.

Pure samples of eugenol were analyzed, and the precision of the method was calculated. Recoveries were calculated by the spiked sample method. Good precision and recoveries were achieved. Due to the lack of accurate information about the mixture of substances present in personal-care products and the need to know the concentration of eugenol due to the importance of this compound as a biocide, the spiked samples method was used to calculate the accuracy.

Methods found in the literature for comparison are listed in Table 3; the listed information reveals that the proposed method can compete with the previous methods for the determination of eugenol in real samples. The other methods mentioned in Table 3 are all accurate, but they suffer from disadvantages such as the need for highcost equipment and the need for those devices for a longer period. By contrast, speed, cost, and ease of use are the advantages of the proposed method in comparison with previous ones Table 3.

\section{- CONCLUSION}

In the proposed derivatization procedure, the concentration of the base used and the reagent were the most sensitive factors in forming the colored product. On the other hand, the speed and time of centrifugation, in addition to the volume of the organic phase, were the most critical factors that determined the value of the distribution ratio in the DLLME of the colored eugenol 
derivative. Dispersive liquid-liquid microextraction, followed by spectrophotometric measurement, was successfully applied to determine eugenol in some locally available personal-care products. Because of the method sensitivity and low detection limit, the DLLME method could be applied to trace eugenol in samples, such as pharmaceutical and environmental samples. This method could be readily extended to analytes other than eugenol that can be oxidatively coupled to PADA.

\section{- ACKNOWLEDGMENTS}

The authors extend their thanks and gratitude to the Department of Biology, University of Baghdad-College of Science, for their assistance, including the equipment, chemicals, bench space, and advice. This research did not receive any specific grant from funding agencies in the public, commercial, or not-for-profit sectors.

\section{- REFERENCES}

[1] Bonilla, J., Poloni, T., Lourenço, R.V., and Sobral, P.J.A., 2018, Antioxidant potential of eugenol and ginger essential oils with gelatin/chitosan films, Food Biosci., 23, 107-114.

[2] Adefegha, S.A., Okeke, B.M., Oboh, G., Ijomone, O.M., and Oyeleye, S.I., 2018, Modulatory effect of eugenol on arginase, nucleotidase, and adenosine deaminase activities of platelets in a carrageenaninduced arthritis rat model: A possible anti-arthritic mechanism of eugenol, Biomed. Pharmacother., 106, 1616-1623.

[3] Sakat, M.S., Kilic, K., Akdemir, F.N.E., Yildirim, S., Eser, G., and Kiziltunc, A., 2018, The effectiveness of eugenol against cisplatin-induced ototoxicity, Braz. J. Otorhinolaryngol., 85 (6), 766-773.

[4] Masghati, S., and Ghoreishi, S.M., 2018, Supercritical $\mathrm{CO}_{2}$ extraction of cinnamaldehyde and eugenol from cinnamon bark: Optimization of operating conditions via response surface methodology, $J$. Supercrit. Fluids, 140, 62-71.

[5] Novato, T., Gomes, G.A., Zeringóta, V., Franco, C.T., de Oliveira, D.R., Melo, D., de Carvalho, M.G., Daemon, E., and de Oliveira Monteiro, C.M., 2018, In vitro assessment of the acaricidal activity of carvacrol, thymol, eugenol and their acetylated derivatives on Rhipicephalus microplus (Acari: Ixodidae), Vet. Parasitol., 260, 1-4.

[6] Nejad, S.M., Özgüneş, H., and Başaran, N., 2017, Pharmacological and toxicological properties of eugenol, Turk. J. Pharm. Sci., 14 (2), 201-206.

[7] Filippou, O., Bitas, D., and Samanidou, V., 2017, Green approaches in sample preparation of bioanalytical samples prior to chromatographic analysis, J. Chromatogr. B, 1043, 44-62.

[8] Abedi, G., Talebpour, Z., and Jamechenarboo, F., 2018, The survey of analytical methods for sample preparation and analysis of fragrances in cosmetics and personal care products, TrAC, Trends Anal. Chem., 102, 41-59.

[9] Kostopoulou, M., and Nikolaou, A., 2008, Analytical problems and the need for sample preparation in the determination of pharmaceuticals and their metabolites in aqueous environmental matrices, TrAC, Trends Anal. Chem., 27 (11), 10231035.

[10] Rundgren, I.M., Bruserud, Ø., Ryningen, A., and Ersvaer, E., 2018, Standardization of sampling and sample preparation for analysis of human monocyte subsets in peripheral blood, J. Immunol. Methods, 461, 53-62.

[11] Nuckowski, Ł., Kaczmarkiewicz, A., and Studzińska, S., 2018, Review on sample preparation methods for oligonucleotides analysis by liquid chromatography, J. Chromatogr. B, 1090, 90-100.

[12] Niu, Z., Zhang, W., Yu, C., Zhang, J., and Wen, Y., 2018, Recent advances in biological sample preparation methods coupled with chromatography, spectrometry and electrochemistry analysis techniques, TrAC, Trends Anal. Chem., 102, 123-146.

[13] Rykowska, I., Ziemblińska, J., and Nowak, I., 2018, Modern approaches in dispersive liquid-liquid microextraction (DLLME) based on ionic liquids: A review, J. Mol. Liq., 259 (1), 319-339.

[14] Wang, Q., Chen, R., Shatner, W., Cao, Y., and Bai, Y., 2018, State-of-the-art on the technique of dispersive Liquid-liquid microextraction, Ultrason. Sonochem., 51, 369-377. 
[15] Mansour, F.R., and Danielson, N.D., 2018, Solventterminated dispersive liquid-liquid microextraction: A tutorial, Anal. Chim. Acta, 1016, 1-11.

[16] Khan, N., and Ali, S.A., 2014, Quantitative determination of Eugenol in aqueous extract of Ocimum sanctum by high performance thin layer chromatography, J. Pharm. Res., 8 (8), 1158-1161.

[17] Aydoğmuş, Z., Yıldız, G., Yılmaz, E.M., and AboulEnein, H.Y., 2018, Determination of eugenol in plants and pharmaceutical form by HPLC with amperometric detection at graphene-modified carbon paste electrode, Graphene Technol., 3 (1), 1-9.

[18] Cantalapiedra, A., Gismera, M.J., Sevilla, M.T., and Procopio, J.R., 2014, Sensitive and selective determination of phenolic compounds from aromatic plants using an electrochemical detection coupled with HPLC method, Phytochem. Anal., 25 (3), 247-254.

[19] Inam, F., Deo, S., and Narkhede, N., 2014, HPLC UV method development and quantification of eugenol from methanolic extracts of some spices, Int. J. Chem. Phys. Sci., 3 (6), 92-102.

[20] Ziyatdinova, G., Ziganshina, E., and Budnikov, H., 2013, Voltammetric sensing and quantification of eugenol using nonionic surfactant self-organized media, Anal. Methods, 5 (18), 4750-4756.

[21] Pramod, K., Ilyas, U.K., Kamal, Y.T., Ahmad, S., Ansari, S.H., and Ali, J., 2013, Development and validation of RP-HPLC-PDA method for the quantification of eugenol in developed nanoemulsion gel and nanoparticles, J. Anal. Sci. Technol., 4 (1), 16.

[22] Hu, G., Zeng, Q., Hu, Y., Shen, X., and Song, J., 2014, Determination of eugenol by using a Briggs Rauscher system catalyzed by a macrocyclic nickel (II) complex, Electrochim. Acta, 136, 33-40.

[23] Marcos, J., and Pozo, O.J., 2015, Derivatization of steroids in biological samples for GC-MS and LCMS analyses, Bioanalysis, 7 (19), 2515-2536.

[24] Bueno, M., Zapata, J., and Ferreira, V., 2014, Simultaneous determination of free and bonded forms of odor-active carbonyls in wine using a headspace solid phase microextraction strategy, $J$. Chromatogr. A, 1369, 33-42.

[25] Faust, S.D., and Anderson, P.W., 1968, Factors influencing the condensation of 4-aminoantipyrine with derivatives of hydroxybenzene-III. A study of phenol content in surface waters, Water Res., 2 (7), 515-525.

[26] Al-Abachi, M.Q., Haddi, H., and Al-Abachi, A.M., 2005, Spectrophotometric determination of amoxicillin by reaction with $N, N$-dimethyl- $p$ phenylenediamine and potassium hexacyanoferrate(III), Anal. Chim. Acta, 554, 184189.

[27] Fiamegos, Y.C., Stalikas, C.D., Pilidis, G.A., and Karayannis, M.I., 2000, Synthesis and analytical applications of 4 -aminopyrazolone derivatives as chromogenic agents for the spectrophotometric determination of phenols, Anal. Chim. Acta, 403 (13), 315-323.

[28] Fadhil, G., 2014, Spectrophotometric determination of thymol in pharmaceutical preparations via oxidative coupling reaction with 2,4dinitrophenylhydrazine in the presence of potassium periodate, Iraqi J. Sci., 55 (1), 27-34.

[29] Barache, U.B., Shaikh, A.B., Lokhande, T.N., Anuse, M.A., Kamble, G.S., Gurame, V.M., and Gaikwad, S.H., 2017, Acid switched efficient, cost effective, selective separation and determination of selenium(IV), J. Environ. Chem. Eng., 5 (5), 48284840.

[30] Szarka, A., Turková, D., and Hrouzková, S., 2018, Dispersive liquid-liquid microextraction followed by gas chromatography-mass spectrometry for the determination of pesticide residues in nutraceutical drops, J. Chromatogr. A, 1570, 126-134.

[31] Barreto, J.A., dos Santos de Assis, R., Cassella, R.J., and Lemos, V.A., 2019, A novel strategy based on in-syringe dispersive liquid-liquid microextraction for the determination of nickel in chocolate samples, Talanta, 193, 23-28. 